\title{
Composição Florística da Comunidade Infestante em Gramados DE Paspalum notatum No MUNICÍPIO DE ASSIS, SP ${ }^{1}$
}

\author{
Floristic Composition of the Weed Community in Paspalum notatum Flügge Turfgrasses \\ in Assis, SP
}

MACIEL, C.D.G. ${ }^{2}$, POLETINE, J.P. ${ }^{2}$, AQUINO, C.J.R. ${ }^{3}$, FERREIRA, D.M. ${ }^{4}$ e MAIO, R.M.D. ${ }^{5}$

\begin{abstract}
RESUMO - Os gramados de Paspalum notatum são os mais disseminados no Brasil, constituindo diferentes locais e propósitos. A infestação por plantas daninhas acarreta perda de qualidade estética quando a finalidade do gramado é ornamental. Com o objetivo de caracterizar a comunidade infestante em gramados de $P$. notatum no municipio de Assis/SP, foi realizado entre os meses de junho e julho de 2004 um levantamento florístico em áreas ensolaradas e sombreadas, sob copas de árvores. Cem amostras de 0,50 x 0,50 m foram coletadas nas duas condições de luminosidade (50 em áreas ensolaradas e 50 em áreas sombreadas), a partir das quais foram calculados os parâmetros freqüência, densidade, abundância, freqüência relativa, densidade relativa, abundância relativa e indice de valor de importância. Ao todo, foram identificadas 45 espécies de plantas daninhas, distribuídas em 15 famílias; Asteraceae apresentou o maior número de espécies nas condições ensolaradas e sombreadas. As espécies mais importantes nas áreas ensolaradas foram: Oxalis latifolia > Desmodium incanum > Cyperus flavus > Cyperus diffusus > Cyperus brevifolius; e nas áreas sombreadas: C. brevifolius $>$ Alternanthera tenella $>$ D. incanum $>$ Elephantopus mollis $>$ C. flavus. Para $80,0 \%$ das amostragens, a massa seca total da parte aérea das espécies de plantas daninhas não sofreu influência das condições ensolarada ou sombreada, constituindo uma produção máxima de aproximadamente $150 \mathrm{~kg} \mathrm{ha}^{-1}$ para ambas as condições.
\end{abstract}

Palavras-chave: plantas daninhas, grama-batatais, gramado, fitossociologia.

ABSTRACT - The Paspalum notatum are the most disseminated turfgrasses in Brazil, constituting different sites and purposes. Weed infestation can lead to loss of turfgrass aesthetic quality when its purpose is ornamental.To characterize the weed community in $\boldsymbol{P}$. notatumturfgrasses in Assis$S P$, a floristic survey was carried out in sunny and shades areas, under tree canopies, during June and July, 2004. One hundred samples of $0.50 \times 0.50 \mathrm{~m}$ collected from sunny and shaded areas (50 in sunny and 50 in shaded), were used to calculate parameter frequency, density, abundance, relative frequency, relative density, relative abundance and importance value index. $A$ total of forty-five weed species were identified, distributed into fifteen families, with Asteraceae presenting the largest number of species under sunny and shaded conditions. The most important species were: Oxalis latifolia > Desmodium incanum > Cyperus flavus > C. diffuses > C. Brevifolius in the sunny areas and $\mathbf{C}$. brevifolius $>$ Alternanthera tenella $>$ D. incanum $>$ Elephantopus mollis > C. Flavus in the shaded areas. For $80 \%$ of the samplings, dry matter total of the aerial part of the weeds was not influenced by the sunny or shaded areas, with a maximum production of approximately $150 \mathrm{~kg} \mathrm{ha}^{-1}$ for both conditions.

Keywords: weeds, bahiagrass, turfgrass, phytosociology.

1 Recebido para publicação em 10.6.2007 e na forma revisada em 27.2.2008.

2 Prof., Dr., Departamento de Fitotecnia, FUNGE/ESAPP, 19700-000, Paraguaçu Paulista-SP, <macielconsultoria@hotmail.com>; ${ }^{3}$ Aluna do Curso de Ciências Biológicas, FCL-UNESP, 19800-000, Assis, SP. ${ }^{4}$ Aluno do Curso de Agronomia, FUNGE/ESAPP, 19700-000, Paraguaçu Paulista-SP. ${ }^{5}$ Eng - -Agr ${ }^{-}$da empresa Gramar - Gramados Marília-SP, distribuidor autorizado ITOGRASS. 


\section{INTRODUÇÃO}

O relvado - camada de plantas rasteiras é o componente básico da maioria dos projetos de jardinagens, pois integra os demais elementos, como árvores, arbustos, canteiros, fontes, etc., servindo harmoniosamente como pano de fundo ao cenário. Quando o relvado é formado por gramíneas, recebe o nome específico de gramado (Plantas \& Flores, 1977). Além do efeito estético que conferem aos parques e jardins, os gramados podem também formar pastagens, cobrir campos esportivos, como de golfe e futebol, atuar na estabilização de encostas e no controle da erosão, entre outras finalidades (Angelis Neto \& Angelis, 1999; Lorenzi, 2000; Raven et al., 2001; Freitas et al., 2002).

Nos Estados Unidos, pesquisas documentam e concluem muitos beneficios dos gramados ao ambiente. Dentre os destaques, encontram-se: proporcionar ajustamento natural, confortável e seguro para divertimento e prática de esportes; liberar oxigênio e manter a temperatura do ar mais confortável; controlar a poluição e reduzir a erosão do solo; purificar e reter a água dos lençóis freáticos; satisfazer o ser humano pela beleza da paisagem, além de valorizar o imóvel (Turfgrass Producers International, 2002).

No Brasil, a maioria dos gramados é formada pela espécie Paspalum notatum, conhecida como grama-batatais, grama-mato-grosso, grama-bahia, grama-forquilha e grama-pensacola, entre outras denominações. É comumente utilizada em diversos locais e com diferentes propósitos, como áreas residenciais, industriais, urbanas e em rodovias (Lorenzi \& Souza, 2001; Freitas et al., 2002). A presença da espécie é muito significativa na região Centro-Sul do Brasil, sendo nativa das Américas Central e do Sul (Demattê, 1983). Aspectos positivos quanto ao seu emprego como forrageira dizem respeito ao fato de ser perene, rústica, adaptarse bem a solos pobres, tolerar o inverno (geadas danificam as folhas sem, contudo, matar as plantas) e suportar pisoteio, apesar de baixa aceitação pelo gado no uso como pastagem (Kissmann, 1997).

A infestação por plantas daninhas acarreta baixa produtividade quando o gramado é utilizado como pastagem e perda de qualidade estética quando tem finalidade ornamental, pois concorrem com os gramados por água, luz, nutriente e espaço, podendo até dizimá-los completamente (Modesto Júnior \&, Mascarenhas, 2001; Freitas et al., 2003). Segundo Lorenzi \& Souza (2001) e Freitas et al. (2003), as plantas daninhas mais freqüentes nesse tipo de gramado são o carrapicho-beiço-de-boi (Desmodium incanum) e a zórnia (Zornia latifolia). Para Demattê (1988), na implantação de gramados, é importante verificar se as placas de grama não estão contaminadas por plantas daninhas, principalmente trevo e tiririca.

Uma breve revisão de literatura demonstrará a ausência de informações sobre a freqüência da comunidade infestante prevalente para esse tipo de gramado nas diferentes regiões do Brasil, assim como a escassez de informações técnicas para implantação e manutenção. Para Barbosa et al. (1997), o fato de as plantas ornamentais e os gramados terem importância pouco reconhecida pelas entidades de pesquisa no País resulta na escassez de informações técnicas, avidamente procuradas pelos potenciais usuários, resultando na importação desenfreada destas e/ou generalização de soluções e recomendações sem base científica.

Este trabalho teve como objetivos identificar a comunidade infestante e estimar seus parâmetros fitossociológicos em gramados de $P$. notatum no município de Assis/SP, considerando a ocorrência das plantas daninhas em condições caracterizadas por áreas ensolaradas e sombreadas, sob copas de árvores.

\section{MATERIAL E MÉTODOS}

O trabalho foi realizado por meio de levantamento florístico em dois gramados de $P$. notatum, entre os meses de junho e julho de 2004, no municipio de Assis/SP. As localidades de estudo foram representadas pelos gramados do campus da UNESP, Faculdade de Ciências e Letras, e do Parque Ecológico "João Domingos Coelho", onde o levantamento foi subdividido considerando amostragens em condições de áreas totalmente ensolaradas e áreas sombreadas, sendo estas últimas representadas pela disposição da infestação abaixo das copas das árvores. Para a condição sob sombreamento das copas das árvores, foram consideradas 
localidades compostas por áreas bem arborizadas, caracterizadas por alta densidade de árvores e tamanho de copas variável, mas que permanentemente mantêm o gramado sombreado durante todo o dia.

Para cada condição de luminosidade, foram arremessados aleatoriamente cem quadrados vazados de madeira (50 em áreas ensolaradas e 50 em áreas sombreadas, sob as copas das árvores), com área interna de $0,25 \mathrm{~m}^{2}(0,50$ x $0,50 \mathrm{~m}$ ), totalizando uma área de $12,5 \mathrm{~m}^{2}$ por condição de luminosidade, de forma semelhante às metodologias descritas por Lara et al. (2003) e Brighenti et al. (2003). As plantas daninhas delimitadas nesta área foram identificadas e contabilizadas de acordo com a espécie, assim como em conjunto coletadas; suas partes aéreas foram separadas em sacos de papel e posteriormente acondicionadas em estufa de secagem com aeração forçada a $65{ }^{\circ} \mathrm{C}$ por um período de três dias, para estimativa da massa seca.

Em função dos dados obtidos, foram estimadas as variáveis: freqüência (indica a ocorrência das espécies em cada quadrado); densidade (indica a quantidade de indivíduos de uma mesma espécie em cada quadrado); abundância (refere-se à concentração das espécies nos diferentes pontos da área total - 50,0 $\mathrm{m}^{2}$ ); freqüência relativa, densidade relativa e abundância relativa (relaciona uma dada espécie a todas as demais encontradas nas áreas); e indice de valor de importância (demonstra as espécies que mais ocorrem em cada área), de forma semelhante aos trabalhos desenvolvidos por Brandão et al. (1998), Lara et al. (2003), Brighenti et al. (2003) e Tuffi Santos et al. (2004).

No cálculo das variáveis foram utilizadas as seguintes fórmulas:

Freqüência $($ Fre $)=\frac{\text { Número de parcelas que contém a espécie }}{\text { Número total de parcelas utilizadas }}$

Densidade $($ Den $)=\frac{\text { Número total de indivíduos por espécie }}{\text { Área total coletada }}$

Abundância $(\mathrm{Abu})=\frac{\text { Número total de indivíduos por espécie }}{\text { Número de parcelas contendo a espécie }}$

Densidade Relativa $($ Drr $)=\frac{\text { Densidade da espécie } \mathrm{x} 100}{\text { Densidade total de todas as espécie }}$

Índice de Valor de Importância (IV) $=$ Frr + Der + Abr
Os dados originais de massa seca da parte aérea das plantas daninhas coletadas através do levantamento foram extrapolados para $\mathrm{kg} \mathrm{ha}{ }^{-1} \mathrm{e}$ representados diretamente na forma de freqüência acumulada, em porcentagem, para as áreas estudadas em condições ensolaradas e sombreadas, sob as copas das árvores.

\section{RESULTADOS E DISCUSSÃO}

O levantamento florístico das plantas daninhas em gramados de $P$. notatum no municipio de Assis/SP totalizou 1.653 e 1.832 individuos, respectivamente, encontrados em áreas ensolaradas e sombreadas por copas de árvores, representadas por 45 espécies, distribuídas em 15 famílias.

Os resultados apresentados nas Tabelas 1 e 2 indicam que as famílias Asteraceae (13), Poaceae (8) e Malvaceae (4) foram as que registraram o maior número de espécies a pleno sol. Nas áreas sob as copas das árvores, a familia Asteraceae também registrou maior número de indivíduos, enquanto a família Poaceae apresentou redução expressiva no número de espécies registradas, em relação às áreas ensolaradas. A redução do número de indivíduos da família Poaceae, nestas áreas, ocorreu, provavelmente, devido ao fato de a maioria das espécies desta família apresentar mecanismo fotossintético do tipo $\mathrm{C}_{4}$, adaptando-se melhor às condições com alta luminosidade. Por outro lado, espécies das famílias Commelinaceae e Brassicaceae, que são mais adaptadas às condições com baixa luminosidade, somente foram observadas nas áreas sombreadas, sob as copas das árvores.

Os resultados corroboram os encontrados por Maimoni-Rodella et al. (1993), os quais observaram que as espécies pertencentes às famílias Asteraceae, Fabaceae e Poaceae foram as que ocorreram em maior número em levantamento em gramados de $P$. notatum, no município de Botucatu-SP. Peixoto et al. (1982), Carvalho \& Pitelli (1992), Cunha \& Brandão (1997) e Lara et al. (2003), em levantamentos florísticos em áreas de culturas e pastagens em várzeas, também verificaram ser a família Asteraceae a de maior número de espécies prevalecentes. Em levantamento fitossociológico em pastagens degradadas de capim-angola e capim-setária, em condições de várzeas, 
Tabela 1 - Relação das espécies de plantas daninhas encontradas em levantamento florístico realizado em gramados de Paspalum notatum, organizadas por família, nome científico e nome popular. Assis-SP, 2004

\begin{tabular}{|c|c|c|}
\hline Família & Nome científico & Nome popular \\
\hline \multirow{2}{*}{ Amaranthaceae } & Alternanthera tenella & Apaga-fogo \\
\hline & Amaranthus lividus & Caruru \\
\hline Apiaceae (Umbelliferae) & Apium leptophyllum & Aipo-bravo \\
\hline \multirow{14}{*}{ Asteraceae } & Ageratum conyzoides & Mentrasto \\
\hline & Bidens pilosa & Picão-preto \\
\hline & Chaptalia nutans & Língua-de-vaca \\
\hline & Chaptalia integerrima & Língua-de-vaca \\
\hline & Conyza bonariensis & Buva \\
\hline & Cosmos sulphureus & Picão-de-flor \\
\hline & Elephantopus mollis & Fumo-bravo \\
\hline & Emilia sonchifolia & Falsa-serralha \\
\hline & Galinsoga quadriradiata & Picão-branco \\
\hline & Gnaphallium spicatum & Erva-macia \\
\hline & Hypochoeris brasiliensis & Almeirão-do-campo \\
\hline & Soliva pterosperma & Roseta \\
\hline & Taraxacum officinale & Dente-de-leão \\
\hline & Tridax procumbens & Erva-de-touro \\
\hline Bignoniaceae & Pyrostegia venusta & Cipó-de-são-joão \\
\hline Brassicaceae & Lepidium ruderale & Mastruz \\
\hline Commelinaceae & Commelina erecta & Trapoeraba \\
\hline \multirow{3}{*}{ Cyperaceae } & Cyperus brevifolius & Tiririca \\
\hline & Cyperus flavus & Tiririca \\
\hline & Cyperus diffusus & Tiririca \\
\hline \multirow{2}{*}{ Euphorbiaceae } & Chamaesyce hyrta & Erva-de-santa-luzia \\
\hline & Phyllanthus tenellus & Quebra-pedra \\
\hline \multirow{3}{*}{ Fabaceae } & Chamaecrista rotundifolia & Acácia-rasteira \\
\hline & Desmodium incanum & Desmódio \\
\hline & Vigna unguiculata & Feijão-miúdo \\
\hline \multirow{4}{*}{ Malvaceae } & Sida rhombifolia & Guanxuma \\
\hline & Sida urens & Guanxuma \\
\hline & Sida glaziovii & Guanxuma-branca \\
\hline & Sida santaremnensis & Guanxuma \\
\hline Ophioglossaceae & Ophioglossum $\mathrm{sp}$ & Samambaia \\
\hline \multirow{3}{*}{ Oxalidaceae } & Oxalis corniculata & Trevo-azedo \\
\hline & Oxalis latifolia & Trevo-azedo \\
\hline & Oxalis corymbosa & Trevo-azedo \\
\hline \multirow{8}{*}{ Poaceae } & Axonopus compressus & Grama-argentina \\
\hline & Brachiaria decumbens & Capim-braquiária \\
\hline & Brachiaria plantaginea & Capim-marmelada \\
\hline & Cynodon dactylon & Grama-seda \\
\hline & Digitaria horizontalis & Capim-colchão \\
\hline & Setaria geniculata & Capim-rabo-de-raposa \\
\hline & Sporobulus indicus & Capim-mourão \\
\hline & Zoysia matrella & Grama-esmeralda \\
\hline Rubiaceae & Richardia brasiliensis & Poaia-branca \\
\hline Solanaceae & Solanum americanum & Maria-pretinha \\
\hline
\end{tabular}


Tabela 2 - Número total de espécies de plantas daninhas organizadas por família, encontradas em levantamento florístico de gramados de Paspalum notatum sob condições de áreas ensolaradas e sombreadas. Assis-SP, 2004

\begin{tabular}{|l|c|c|c|}
\hline \multirow{2}{*}{ Família } & \multicolumn{2}{c|}{$\mathrm{N}^{\mathrm{o}}$ de espécie } & \multirow{2}{*}{ Total } \\
\cline { 2 - 3 } & $\begin{array}{c}\text { Área } \\
\text { ensolarada }\end{array}$ & $\begin{array}{c}\text { Área } \\
\text { sombreada }\end{array}$ & \\
\hline Asteraceae & 13 & 13 & 13 \\
\hline Poaceae & 8 & 3 & 8 \\
\hline Malvaceae & 4 & 3 & 4 \\
\hline Cyperaceae & 3 & 3 & 3 \\
\hline Fabaceae & 3 & 3 & 3 \\
\hline Oxalidaceae & 3 & 3 & 3 \\
\hline Euphobiaceae & 2 & 2 & 2 \\
\hline Amaranthaceae & 2 & 2 & 2 \\
\hline Rubiaceae & 1 & 1 & 1 \\
\hline Apiaceae (Umbelliferae) & 1 & 1 & 1 \\
\hline Bignoniaceae & 1 & 1 & 1 \\
\hline Ophiglossaceae & 1 & 1 & 1 \\
\hline Commelinaceae & 0 & 1 & 1 \\
\hline Solanaceae & 1 & 0 & 1 \\
\hline Brassicaceae & 0 & 1 & 1 \\
\hline \multicolumn{1}{|c|}{ Total } & 43 & 38 & 45 \\
\hline
\end{tabular}

Tuffi Santos et al. (2004) verificaram que as famílias mais representativas foram Poaceae, Asteraceae e Papilioniodeae.

Nas Tabelas 3 e 4 estão apresentadas as composições florísticas das plantas daninhas encontradas sob as condições ensolaradas e sombreadas, assim como os parâmetros fitossociológicos. Em ordem decrescente, as cinco espécies que registraram as maiores freqüências nas áreas ensolaradas foram Desmodium incanum (Fabaceae), Emilia sonchifolia (Asteraceae), Brachiaria decumbens (Poaceae), Cyperus diffusus (Cyperaceae) e Cyperus flavus (Cyperaceae), e em áreas sombreadas foram D. incanum, E. sonchifolia, Alternanthera tenella (Amaranthaceae), Apium leptophyllum (Apiaceae) e C. flavus (Cyperaceae). Com relação à densidade, destacaram-se nas áreas ensolaradas as espécies da família Cyperaceae, representadas por $C$. diffusus $\left(3,58\right.$ plantas $\left.\mathrm{m}^{-2}\right)$, C. flavus $\left(3,48\right.$ plantas $\left.\mathrm{m}^{-2}\right)$ e C. brevifolius $\left(3,46\right.$ plantas $\left.\mathrm{m}^{-2}\right)$, e, nas áreas sombreadas, as espécies $A$. tenella $\left(6,12\right.$ plantas $\left.\mathrm{m}^{-2}\right)$ e C. brevifolius $\left(6,10\right.$ plantas $\left.\mathrm{m}^{-2}\right)$.
Quanto à abundância - parâmetro importante que revela as espécies que apareceram em reboleiras - destacaram-se no levantamento as espécies Oxalis latifolia, A. leptophyllum, Cosmos sulphureus e $C$. brevifolius para as áreas sob condições ensolaradas (Tabela 3), assim como $C$. brevifolius e O. latifolia, para as áreas sombreadas (Tabela 4). Nesse sentido, a abundância pode ser importante para indicar as ações para controle das referidas espécies, uma vez que, segundo Deuber (1997), Christoffoleti $\&$ Aranda (2001) e Freitas et al. (2003), no Brasil estudos sobre o manejo de plantas infestantes em gramados e a seletividade de herbicidas ainda são escassos.

Com relação ao valor de importância (IVI), as cinco principais espécies presentes no levantamento, em ordem decrescente de importância, nas áreas sob condição ensolarada (Tabela 3) foram: O. latifolia $>D$. incanum $>C$. flavus $>C$. diffusus $>C$. brevifolius, e nas áreas sob condição sombreada: $C$. brevifolius $>A$. tenella $>$ D. incanum $>$ Elephantopus mollis $>C$. flavus (Tabela 4). Entretanto, para a massa seca total da parte aérea das espécies registradas em áreas sob condição ensolarada e sombreada, pelas copas das árvores (Figura 1), verificou-se que aproximadamente $80 \%$ das amostragens não sofreram influência da luminosidade, sendo caracterizadas pela produção entre 0,4 e $150 \mathrm{~kg} \mathrm{ha}^{-1}$, para ambas as condições estudadas.

É importante ressaltar que o conhecimento prévio da composição florística das plantas daninhas em gramados, assim como do comportamento delas em diferentes condições, permite antecipar a organização de estratégias preventivas e/ou de menor impacto fisiológico e estético, sobretudo no caso do manejo da infestação através do uso de herbicidas. Nesse contexto, como foram poucas as espécies infestantes dominantes nas diferentes localidades, recomenda-se a adoção de medidas de controle e/ou erradicação das espécies de maior ocorrência, por meio de monda, capina ou aplicação de herbicidas seletivos, assim como a continuidade do monitoramento e prevenção para se evitar o aumento das espécies de menor ocorrência. 
Tabela 3 - Relação das espécies de plantas daninhas encontradas em levantamento florístico de gramados de Paspalum notatum, sob condições ensolaradas, no Município de Assis/SP. Assis-SP, 2004

\begin{tabular}{|c|c|c|c|c|c|c|c|c|c|}
\hline Espécie & $\begin{array}{l}\mathrm{N}^{\mathrm{o}} \mathrm{de} \\
\text { parc. }\end{array}$ & $\begin{array}{l}\mathrm{N}^{\mathrm{o}} \mathrm{de} \\
\text { indiv. }\end{array}$ & Fre & Den & $\mathrm{Abu}$ & $\begin{array}{l}\text { Frr } \\
(\%)\end{array}$ & $\begin{array}{l}\text { Der } \\
(\%)\end{array}$ & $\begin{array}{l}\text { Abr } \\
(\%)\end{array}$ & $\begin{array}{l}\text { IVI } \\
(\%)\end{array}$ \\
\hline Oxalis latifolia & 1 & 67 & 0,01 & 1,34 & 67 & 0,31 & 4,05 & 26,08 & 30,44 \\
\hline Desmodium incanum & 39 & 137 & 0,39 & 2,74 & 4 & 11,93 & 8,29 & 1,37 & 21,58 \\
\hline Cyperus flavus & 18 & 179 & 0,18 & 3,58 & 10 & 5,50 & 10,83 & 3,87 & 20,20 \\
\hline Cyperus diffusus & 21 & 174 & 0,21 & 3,48 & 8 & 6,42 & 10,53 & 3,22 & 20,17 \\
\hline Cyperus brevifolius & 11 & 173 & 0,11 & 3,46 & 16 & 3,36 & 10,47 & 6,12 & 19,95 \\
\hline Brachiaria decumbens & 26 & 92 & 0,26 & 1,84 & 4 & 7,95 & 5,57 & 1,38 & 14,89 \\
\hline Cosmos sulphureus & 6 & 101 & 0,06 & 2,02 & 17 & 1,83 & 6,11 & 6,55 & 14,50 \\
\hline Emilia sonchifolia & 34 & 57 & 0,34 & 1,14 & 2 & 10,40 & 3,45 & 0,65 & 14,50 \\
\hline Tridax procumbens & 15 & 96 & 0,15 & 1,92 & 6 & 4,59 & 5,81 & 2,49 & 12,89 \\
\hline Apium leptophyllum & 5 & 82 & 0,05 & 1,64 & 16 & 1,53 & 4,96 & 6,38 & 12,87 \\
\hline Ophioglossum sp. & 11 & 72 & 0,11 & 1,44 & 7 & 3,36 & 4,36 & 2,55 & 10,27 \\
\hline Alternanthera tenella & 12 & 71 & 0,12 & 1,42 & 6 & 3,67 & 4,30 & 2,30 & 10,27 \\
\hline Oxalis corniculata & 10 & 59 & 0,10 & 1,18 & 6 & 3,06 & 3,57 & 2,30 & 8,92 \\
\hline Chamaecrista rotundifolia & 13 & 33 & 0,13 & 0,66 & 3 & 3,98 & 2,00 & 0,99 & 6,96 \\
\hline Cynodon dactylon & 8 & 36 & 0,08 & 0,72 & 5 & 2,45 & 2,18 & 1,75 & 6,38 \\
\hline Soliva pterosperma & 1 & 13 & 0,01 & 0,26 & 13 & 0,31 & 0,79 & 5,06 & 6,15 \\
\hline Elephantopus mollis & 11 & 27 & 0,11 & 0,54 & 2 & 3,36 & 1,63 & 0,96 & 5,95 \\
\hline Bidens pilosa & 7 & 26 & 0,07 & 0,52 & 4 & 2,14 & 1,57 & 1,45 & 5,16 \\
\hline Sida glaziovii & 7 & 21 & 0,07 & 0,42 & 3 & 2,14 & 1,27 & 1,17 & 4,58 \\
\hline Sida santaremnensis & 2 & 16 & 0,02 & 0,32 & 8 & 0,61 & 0,97 & 3,11 & 4,69 \\
\hline Oxalis corymbosa & 1 & 8 & 0,01 & 0,16 & 8 & 0,31 & 0,48 & 3,11 & 3,90 \\
\hline Sida urens & 4 & 15 & 0,04 & 0,30 & 4 & 1,22 & 0,91 & 1,46 & 3,59 \\
\hline Gnaphallium spicatum & 11 & 2 & 0,11 & 0,04 & 0 & 3,36 & 0,12 & 0,07 & 3,56 \\
\hline Phyllanthus tenellus & 7 & 12 & 0,07 & 0,24 & 2 & 2,14 & 0,73 & 0,67 & 3,53 \\
\hline Pyrostegia venusta & 6 & 9 & 0,06 & 0,18 & 2 & 1,83 & 0,54 & 0,58 & 2,96 \\
\hline Galinsoga quadriradiata & 2 & 9 & 0,02 & 0,18 & 5 & 0,61 & 0,54 & 1,75 & 2,91 \\
\hline Vigna unguiculata & 4 & 9 & 0,04 & 0,18 & 2 & 1,22 & 0,54 & 0,88 & 2,64 \\
\hline Ageratum conyzoides & 2 & 7 & 0,02 & 0,14 & 4 & 0,61 & 0,42 & 1,36 & 2,40 \\
\hline Setaria geniculata & 2 & 7 & 0,02 & 0,14 & 4 & 0,61 & 0,42 & 1,36 & 2,40 \\
\hline Chaptalia nutans & 4 & 7 & 0,04 & 0,14 & 2 & 1,22 & 0,42 & 0,68 & 2,33 \\
\hline Solanum americanum & 2 & 6 & 0,02 & 0,12 & 3 & 0,61 & 0,36 & 1,17 & 2,14 \\
\hline Zoysia matrella & 1 & 4 & 0,01 & 0,08 & 4 & 0,31 & 0,24 & 1,56 & 2,10 \\
\hline Chaptalia integerrima & 3 & 5 & 0,03 & 0,10 & 2 & 0,92 & 0,30 & 0,65 & 1,87 \\
\hline Richardia brasiliensis & 5 & 2 & 0,05 & 0,04 & 0 & 1,53 & 0,12 & 0,16 & 1,81 \\
\hline Chamaesyce hyrta & 3 & 4 & 0,03 & 0,08 & 1 & 0,92 & 0,24 & 0,52 & 1,68 \\
\hline Brachiaria plantaginea & 1 & 3 & 0,01 & 0,06 & 3 & 0,31 & 0,18 & 1,17 & 1,65 \\
\hline Sida rhombifolia & 3 & 3 & 0,03 & 0,06 & 1 & 0,92 & 0,18 & 0,39 & 1,49 \\
\hline Taraxacum officinale & 3 & 3 & 0,03 & 0,06 & 1 & 0,92 & 0,18 & 0,39 & 1,49 \\
\hline Sporobulus indicus & 1 & 2 & 0,01 & 0,04 & 2 & 0,31 & 0,12 & 0,78 & 1,21 \\
\hline Conyza bonariensis & 1 & 1 & 0,01 & 0,02 & 1 & 0,31 & 0,06 & 0,39 & 0,76 \\
\hline Axonopus compressus & 1 & 1 & 0,01 & 0,02 & 1 & 0,31 & 0,06 & 0,39 & 0,76 \\
\hline Digitaria horizontalis & 1 & 1 & 0,01 & 0,02 & 1 & 0,31 & 0,06 & 0,39 & 0,76 \\
\hline Amaranthus lividus & 1 & 1 & 0,01 & 0,02 & 1 & 0,31 & 0,06 & 0,39 & 0,76 \\
\hline Total & 327 & 1.653 & 3,27 & 33,06 & 256,9 & 100 & 100 & 100 & 300 \\
\hline
\end{tabular}

№ de parc. $=$ oo de parcelas em que a espécie foi encontrada; № de indiv. $=$ no total de indivíduos por espécie; Fre $=$ freqüência; Den $=$ densidade $\left(\right.$ plantas $\left.\mathrm{m}^{-2}\right) ; \mathrm{Abu}=$ abundância; $\mathrm{Frr}=$ freqüência relativa; Der = densidade relativa; $\mathrm{Abr}=$ abundância relativa; IVI $=$ índice de valor de importância. 
Composição florística da comunidade infestante em gramados...

Tabela 4 - Relação das espécies de plantas daninhas encontradas em levantamento florístico de gramados de Paspalum notatum, sob condições sombreadas, no município de Assis/SP, em 2004

\begin{tabular}{|c|c|c|c|c|c|c|c|c|c|}
\hline Espécie & $\begin{array}{l}\mathrm{N}^{\mathrm{o}} \mathrm{de} \\
\text { Parc. }\end{array}$ & $\begin{array}{l}\mathrm{N}^{\mathrm{o}} \mathrm{de} \\
\text { Indiv. }\end{array}$ & Fre & Den & $\mathrm{Abu}$ & $\begin{array}{l}\text { Frr } \\
(\%)\end{array}$ & $\begin{array}{l}\text { Der } \\
(\%)\end{array}$ & $\begin{array}{l}\text { Abr } \\
(\%)\end{array}$ & IVI \\
\hline Cyperus brevifolius & 6 & 305 & 0,06 & 6,10 & 51 & 1,78 & 16,65 & 23,46 & 41,88 \\
\hline Alternanthera tenella & 27 & 306 & 0,27 & 6,12 & 11 & 7,99 & 16,70 & 5,23 & 29,92 \\
\hline Desmodium incanum & 44 & 118 & 0,44 & 2,36 & 3 & 13,02 & 6,44 & 1,24 & 20,70 \\
\hline Elephantopus mollis & 18 & 139 & 0,18 & 2,78 & 8 & 5,33 & 7,59 & 3,56 & 16,48 \\
\hline Cyperus flavus & 24 & 124 & 0,24 & 2,48 & 5 & 7,10 & 6,77 & 2,38 & 16,25 \\
\hline Oxalis latifolia & 1 & 24 & 0,01 & 0,48 & 24 & 0,30 & 1,31 & 11,08 & 12,68 \\
\hline Cyperus diffusus & 12 & 97 & 0,12 & 1,94 & 8 & 3,55 & 5,29 & 3,73 & 12,58 \\
\hline Emilia sonchifolia & 28 & 51 & 0,28 & 1,02 & 2 & 8,28 & 2,78 & 0,84 & 11,91 \\
\hline Richardia brasiliensis & 13 & 89 & 0,13 & 1,78 & 7 & 3,85 & 4,86 & 3,16 & 11,86 \\
\hline Ophioglossum sp. & 9 & 76 & 0,09 & 1,52 & 8 & 2,66 & 4,15 & 3,90 & 10,71 \\
\hline Oxalis corniculata & 18 & 69 & 0,18 & 1,38 & 4 & 5,33 & 3,77 & 1,77 & 10,86 \\
\hline Sida rhombifolia & 17 & 61 & 0,17 & 1,22 & 4 & 5,03 & 3,33 & 1,66 & 10,02 \\
\hline Apium leptophyllum & 25 & 26 & 0,25 & 0,52 & 1 & 7,40 & 1,42 & 0,48 & 9,30 \\
\hline Hypochoeris brasiliensis & 15 & 51 & 0,15 & 1,02 & 3 & 4,44 & 2,78 & 1,57 & 8,79 \\
\hline Gnaphallium spicatum & 7 & 55 & 0,07 & 1,10 & 8 & 2,07 & 3,00 & 3,63 & 8,70 \\
\hline Sida urens & 3 & 31 & 0,03 & 0,62 & 10 & 0,89 & 1,69 & 4,77 & 7,35 \\
\hline Brachiaria decumbens & 3 & 29 & 0,03 & 0,58 & 10 & 0,89 & 1,58 & 4,46 & 6,93 \\
\hline Conyza bonariensis & 3 & 28 & 0,03 & 0,56 & 9 & 0,89 & 1,53 & 4,31 & 6,72 \\
\hline Phyllanthus tenellus & 10 & 26 & 0,10 & 0,52 & 3 & 2,96 & 1,42 & 1,20 & 5,58 \\
\hline Galinsoga quadriradiata & 6 & 26 & 0,06 & 0,52 & 4 & 1,78 & 1,42 & 2,00 & 5,19 \\
\hline Axonopus compressus & 7 & 22 & 0,07 & 0,44 & 3 & 2,07 & 1,20 & 1,45 & 4,72 \\
\hline Chaptalia nutans & 4 & 13 & 0,04 & 0,26 & 3 & 1,18 & 0,71 & 1,50 & 3,39 \\
\hline Cynodon dactylon & 4 & 11 & 0,04 & 0,22 & 3 & 1,18 & 0,60 & 1,27 & 3,05 \\
\hline Commelina erecta & 6 & 9 & 0,06 & 0,18 & 2 & 1,78 & 0,49 & 0,69 & 2,96 \\
\hline Sida glaziovii & 5 & 9 & 0,05 & 0,18 & 2 & 1,48 & 0,49 & 0,83 & 2,80 \\
\hline Pyrostegia venusta & 2 & 7 & 0,02 & 0,14 & 4 & 0,59 & 0,38 & 1,62 & 2,59 \\
\hline Oxalis corymbosa & 1 & 3 & 0,01 & 0,06 & 3 & 0,30 & 0,16 & 1,38 & 1,84 \\
\hline Chaptalia integerrima & 3 & 4 & 0,03 & 0,08 & 1 & 0,89 & 0,22 & 0,62 & 1,72 \\
\hline Ageratum conyzoides & 2 & 3 & 0,02 & 0,06 & 2 & 0,59 & 0,16 & 0,69 & 1,45 \\
\hline Tridax procumbens & 2 & 3 & 0,02 & 0,06 & 2 & 0,59 & 0,16 & 0,69 & 1,45 \\
\hline Cosmos sulphureus & 2 & 3 & 0,02 & 0,06 & 2 & 0,59 & 0,16 & 0,69 & 1,45 \\
\hline Chamaecrista rotundifolia & 2 & 3 & 0,02 & 0,06 & 2 & 0,59 & 0,16 & 0,69 & 1,45 \\
\hline Vigna unguiculata & 2 & 3 & 0,02 & 0,06 & 2 & 0,59 & 0,16 & 0,69 & 1,45 \\
\hline Bidens pilosa & 1 & 2 & 0,01 & 0,04 & 2 & 0,30 & 0,11 & 0,92 & 1,33 \\
\hline Amaranthus lividus & 2 & 2 & 0,02 & 0,04 & 1 & 0,59 & 0,11 & 0,46 & 1,16 \\
\hline Taraxacum officinale & 2 & 2 & 0,02 & 0,04 & 1 & 0,59 & 0,11 & 0,46 & 1,16 \\
\hline Lepidium ruderale & 1 & 1 & 0,01 & 0,02 & 1 & 0,30 & 0,05 & 0,46 & 0,81 \\
\hline Chamaesyce hyrta & 1 & 1 & 0,01 & 0,02 & 1 & 0,30 & 0,05 & 0,46 & 0,81 \\
\hline Total & 338 & 1.832 & 3,38 & 36,64 & 216,7 & 100 & 100 & 100 & 300 \\
\hline
\end{tabular}

№ de parc. $=\mathrm{n}^{\mathrm{o}}$ de parcelas em que a espécie foi encontrada; № de indiv. $=\mathrm{n}^{\circ}$ total de indivíduos por espécie; Fre $=$ freqüência; Den $=$ densidade $\left(\right.$ plantas $\left.\mathrm{m}^{-2}\right) ; \mathrm{Abu}=$ abundância; Frr $=$ freqüência relativa; Der $=$ densidade relativa; Abr $=$ abundância relativa; IVI $=$ índice de valor de importância. 


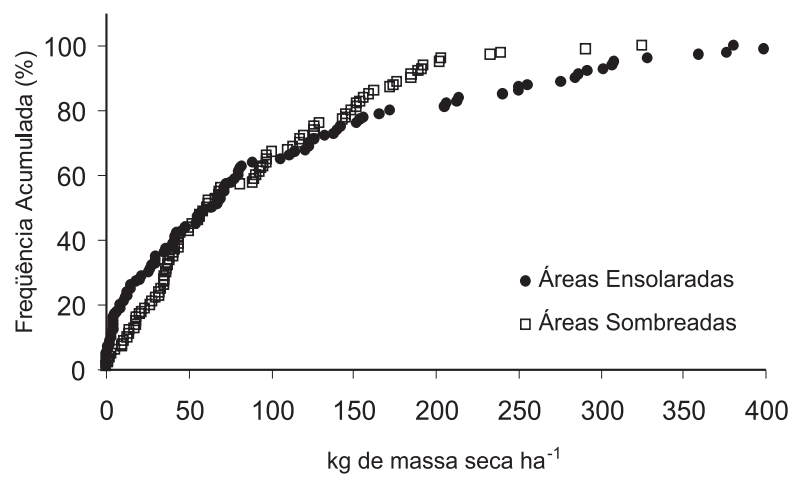

Figura 1 - Freqüência acumulada (\%) da massa seca da parte aérea das plantas daninhas encontradas no levantamento florístico em gramados de Paspalum notatum, em condições ensolaradas e sombreadas, sob as copas das árvores, no município de Assis/SP, em 2004.

\section{LITERATURA CITADA}

ANGELIS NETO, G.; ANGELIS, B. L. D. Plantas ornamentais: do paisagismo a outras aplicações. R. Bras. Hortic. Ornam., v. 5, n. 1, p. 12-19, 1999.

BARBOSA, J. G. et al. Plantio de gramados de Paspalum notatum Flügge "batatais": tipos de mudas e doses de fertilizantes. R. Bras. Hortic. Ornam., v. 3, n. 2, p. 50-54, 1997.

BRANDÃO, M.; BRANDÃO, H.; LACA-BUENDIA, J. P. A mata ciliar do rio Sapucaí, município de Santa Rita do Sapucaí-MG: fitossociologia. Daphne, v. 8, n. 4, p. 36-48, 1998.

BRIGHENTI, A. M. et al. Cadastramento fitossociológico de plantas daninhas na cultura do girassol no município de Chapadão do Céu, GO. B. Inf. SBCOD, v. 9, n. 1, p. 5-8, 2003.

CARVALHO, S. L.; PITELLI, R. A. Levantamento e análise fitossociológica das principais espécies de plantas daninhas de pastagens da região de Selvíria-MS. Planta Daninha, v. 10, n. $1 / 2$, p. $25-32,1992$.

CHRISTOFFOLETI, P. J.; ARANDA, A. N. Seletividade de herbicidas a cinco tipos de gramas. Planta Daninha, v. 19, n. 2 , p. $273-278,2001$

CUNHA, L. H.; BRANDÃO, M. Plantas daninhas em culturas em áreas de várzea no município de Governador Valadares, MG. Daphne, v. 7, n. 1, p. 60-68, 1997.

DEMATTÊ, M. E. S. P. Aplicação de nitrogênio, fósforo, potássio, adubo orgânico e calcário dolomítico na produção de sementes de grama-batatais (Paspalum notatum Flügge) em Latossol Vermelho Escuro. 1983. 34 f. Tese (Doutorado em Agronomia) - Escola Superior de Agricultura 'Luiz de Queiroz", Piracicaba, 1983.
DEMATTÊ, M. E. S. P. Implantação e manutenção de jardins. In: GRAZIANO T. T. Jardinagem. Jaboticabal: FCAV, 1988. p. 71-95.

DEUBER, R. Manejo de plantas daninhas em áreas não agrícolas. In: DEUBER. R. Ciência das plantas

infestantes: manejo. Campinas: Edição do Autor. 1997. v. 2 p. $273-275$

FREITAS, F. C. L. et al. Efeitos do trinexapac-ethyl sobre o crescimento e florescimento da grama-batatais. Planta

Daninha, v. 20, n. 3, p. 477-486, 2002.

FREITAS, F. C. L. et al. Eficiência do triclopyr no controle de plantas daninhas em gramado (Paspalum notatum).

Planta Daninha, v. 21, n. 1, p. 159-164, 2003.

KISSMANN, K. G. Plantas infestantes e nocivas. 2. ed. São Paulo: BASF, 1997. Tomo I. p. 679-684.

LORENZI, H. Plantas daninhas do Brasil: terrestres, aquáticas, parasitas e tóxicas. 3.ed. Nova Odessa: Plantarum, 2000. $349 \mathrm{p}$

LORENZI, H.; SOUZA, H. M. Plantas ornamentais do Brasil: arbustivas, herbáceas e trepadeiras. 3.ed. Nova Odessa: Plantarum, 2001. 558 p.

LARA, J. F. R.; MACEDO, J. F.; BRANDÃO, M. Plantas daninhas em pastagens de várzeas no Estado de Minas Gerais. Planta Daninha, v. 21, n. 1, p. 11-20, 2003

MAIMONI-RODELLA, R. C. S. et al. Levantamento da comunidade de plantas daninhas ocorrentes em áreas de gramados em Botucatu-SP. In: CONGRESSO BRASILEIRO DA CIÊNCIA DAS PLANTAS DANINHAS, 19., 1993, Londrina. Resumos... Londrina: SBHED, 1993. p. 79

MODESTO JÚNIOR, M. S.; MASCARENHAS, R. E. B. Levantamento da infestação de plantas daninhas associadas a uma pastagem cultivada de baixa produtividade no nordeste paraense. Planta Daninha, v. 19, n. 1, p. 11-21, 2001.

PEIXOTO, A. L.; CARVALHO, S. M.; ROSA, M. M. T. Análise botânica de um campo de pastagem no Estado do Rio de Janeiro. Planta Daninha, v. 5, n. 2, p. 1-7, 1982.

PLANTAS e flores. São Paulo: Abril Cultural, 1977. v. 2. 314 p

RAVEN, P. H.; EVERT, R. F.; EICHHORN, S. E. Biologia vegetal. Tradução Antonio Salatino et al. 6.ed. Rio de Janeiro: Guanabara Koogan, 2001. p. 237

TUFFI SANTOS, L. D. et al. Levantamento fitossocilógico em pastagens degradadas sob condições de várzeas. Planta Daninha, v. 22, n. 3, p. 343-349, 2004.

TURFGRASS PRODUCERS INTERNATIONAL. Turfgrass - functional, recreational e aesthetic. Turf Resource Center, 2002. Disponível em: $<\mathrm{http} / /$ www.turgrasssod.org/trc/statistics.html>. Acesso em: 28 nov. 2002 